\section{Origens e evolução da história em quadrinhos}

Maria Beatriz Rahde Professora FAMECOS/ PUCRS Doutoranda em Educação/ PUCRS
DESDE a PréHistória podem-se verificar re gistros de imagens exercitadas pelo homem, com traçados representativos deanimais selvagensquecercavameameaçavama existência e o universo primitivos.

N o entanto, por que ou com quepropósito teria o homem começado a desenhar imagensgráficas, estruturadasnumaseqüência narrativa, no interior das cavernas?

De acordo com Gaiarsa (1970, p. 115):

"Os acadêmicos ... dizem que os dese nhos famosos das cavernas pré-históricas - que foram a primei ra história em quadrinhos que já se fez eram um 'ensaio de controlar magicamente o mundo' .... Ora ... estes desenhos controlavam ... a realidade e eram mágicos sem mais."

Certamente os traçados e as modelagens executados pelos homens primitivos, teriam sido o indício dos primeiros signos que ocasionariam, posteriormente, estudos interpretativos da intel igência emergenteno mundo pré-histórico.

Frente aos perigos de um meio hostil, o homem descobria, sem mesmo o saber, a sua capacidade criadora através da imagem, não só comunicando, mas produzindo cultura.

É possível acreditar que, destes primeiros artistas que exercitavam ludicamente as próprias mãos, as quais aparecem muitas vezes superpostas aos desenhos das cavernas, nasceram as primeiras seqüências de imagens, que permitiram aos antropólogos maior conhecimento das culturas primitivas, pela sua iconografia. Foi assim quea História da Arteencontrou possibilidades deidentificação e descoberta deel ementos de continuidade cultural, a partir do estudo da arte da Pré-História. 
Considerando que a técnica narrativa, isto é, uma história por trás da imagem, já aparece na Era Magdaleniana, aproximadamente de 15.000 a 10.000 anos a.C. , um exemplo desta narrativa é representada pelo acasalamento de bisontes ( 0 mundo da A rte, 1979, p.17):

“Estefamoso grupo naturalístico ... foi modelado em argila sobre um pedaço de rocha. Mostra claramente a finalidade mágica da artedo homem primitivo: a procriação e a caça."

Constata-se, desta forma, que o desenho, a pintura e a modelagem não eram executados, apenas, semnenhum propósito, mas "contavam" um fato percebido pela ótica do homem primitivo.

Bem mais adiante na história da civilização, as pinturas e os relevos egípcios continuaram esta narrativa através das imagens pintadas ou modeladas no interior dos templos, nos túmulos, nos quais apareciam figuras do faraó, da corte, reportando episódios repletos de símbolos e que representavam cenas de caçadas, de colheitas, de oferendas ou mesmo cenas domésticas.

Um dos muitosmotivos, brilhantemente executado em pedra calcária pintada, é o relevo do Túmulo deTi, em Saqqara, aproximadamenteentre2.480e2.350a.C., que“ilustra episódios da vida cotidiana" (0 M undo da A rte, 1979, p. 136).

Estas imagens, além de proporcionar inestimáveis produções e informações culturais, fornecerameai nda fornecem, elementos de comunicação social sobre os valores e a sensibilidade humanas, então apoiadas pela escrita cuneiforme, queexplicava a narrativa histórica, reforçando o poder iconográfico formal.

Conforme Gaiarsa (1970, p. 116), “a primeira forma de escrita conhecida - os hieróglifos do Egito - foi o segundo tipo de história em quadrinhos que a humanidade conheceu."

Em facedo exposto, éimportantefornecer uma definição sintética das histórias em quadrinhos: " Elas são formadas por dois códigos de signos gráficos: a imagem e a linguagemescrita" (Luyten 1985, p.11), numa seqüência narrativa contínua.

Entretanto, a história em quadrinhos atual possui maisumelemento gráfico nasua composição, queaparececomo um prolongamento do personagem, o que proporciona maior dinamização na leitura: são os chamados balões.

Cabe pois sal ientar que, no percurso de sua evolução, a imagem permaneceu contando histórias. O balão, considerado um elemento recente na moderna história em quadrinhos, manifestou-se já na Idade Média (Moya 1993) como no conjunto da cena da A doração de Cristo, extraída do Manuscrito do A pocalipse - aproximadamente em 1230 - e na famosa xilogravura de Protat, de 1370. N esta última, a "narrativa" é a crucificação de Cristo onde, ao pé da Cruz, um centurião romano aponta para cima e da sua boca se desenrola um pergaminho com a seguinte inscrição eml etras góticas: “ N a verdade, Este era o Filho de Deus".

Percebe-se, assim, dizem Couperie e outros (1970, p.9), que:

“O advento da história em quadrinhos foi preparado comumalonga evolução, cuja amplitude ultrapassa muito o domínio de seus primeiros protótipos na arte figurativa."

Pouco a pouco, a imagem adaptou-se aostextos, principalmenteno séculoXV, quandoaxilogravura começou aser utilizadapara ilustrar livros. No séculoXVI, oflorescimento desta técnica passou a desempenhar um notável papel, constituindo-se num elemento essencial da conjugação imagem/ texto.

Por esta razão e pela nova técnica de escavar a madeira - a gravura de topo - a xilogravura foi retomada no século XIX com repercussões decisivas pela reaproximação da imagem com o texto, separados, anteriormente, com o aparecimento da litografia no século XVIII, recolocando a imagemnacontinuidadeenavidadahistória 
(Couperie et al., 1970).

Foi desta forma quea ilustração obteve um extraordinário desenvolvimento a partir de 1830, reproduzindo com imagens, por exemplo, Paul et Virginie, sem esquecer a imensa obra de Gustave Doré.

Outro fator de importância foram as ilustrações do famoso desenhista da época, o inglês George Cruikshank, da obra Oliver Twist, cujo autor Charles Dickens era quase desconhecido.

Dickens, editor de periódicos como Bentley's M iscellany, Household Worlds e All the Year Round, que publicava seus romances em fascículos eseusartigos humorísticos em vários periódicos, era considerado um simples argumentista do já importante e conhecido artista Cruikshank, desenhista de revistas satíricas da vida política da Inglaterra.

A ssim, a ascensão de Dickens começou a verificar-se com a obra Pickwick Papers e principalmente com o romance O liver T wist (1838), devido às imagens primorosas de George Cruikshank junto ao texto.

As pesquisas com as possibilidades da forma continuaram e o cartaz passou a ser considerado e apreciado como obra de arte. Os ilustradores e criadores foram atraídos pela revolução epelainvasão da imagem que aparecia por toda parte e, neste cenário de iconografia eexplosão decores, a valorização do artista foi um fator de grande influência sobre a história em quadrinhos.

É importantesalientar quea descoberta da fotografia, aparecendo no século passado num jornal inglês, multiplicou a presença da imagem. Pouco depois, pela decomposição dafotografia, quadro por quadro, foi possível a recomposi ção do movimento com o cinema, em 1895.

Os "comics" verdadeiramente modernoscomeçaramaaparecer: em 1889naFrança e em 1896, com a forma atual, nos Estados Unidos da América.

Portanto o cinemae, em conseqüência, o desenho animado, bem como a história em quadrinhos, nasceram simultaneamente, não derivando uns dos outros, mas incorporando uma profundatendência do homem nabusca da união da imagem, presente na expressão humana, comalinguagem escritaeposteriormentefalada, pela evolução do cinema sonoro, ao final da segunda década do século XX.

Do ponto de vista cultural era grandeo interesse popular pela representação imagística nesteperíodo. Estasuperavatodas as preferências, principalmente pela leitura dos periódicos enriquecidos com desenhos. Coma (1979, p. 9) reflete que:

“Tudo confluía em atração diante do amplo conteúd o gráfico da imprensa; e, quando esta descobriu a cor e advertiu que o melhor emprego da mesma se conseguia a partir de desenhos... o primeiro passo para a origem das histórias em quadrinhos estava dado."

Percebe-se, portanto, que a nova forma delinguagem quesurgia, criava outrossignificados, novos valores que possuíam intensa relação com a cultura da época. A linguagem dosquadrinhos, provavelmente de forma inconscienteao leitor, estava criando sensações de profunda significação cultural e social, já que, conforme Duarte Jr. (1981), a atitude valorativa situando-se primordialmente na esfera do "sentir" éanterior à "razão".

"O Sonho Manufaturado", como o definiu Gombrich (1986), tem sido uma adaptação da linguagem do quadrinho como meio de informação e comunicação. Peltzer (1991) considera, ao mesmo tempo, que seu efeito é notavelmente narrativo e cênico.

Exercendo também um papel que deve ser analisado numa perspectiva de meio de comunicação, Klawa e Cohen (1970, p.108) ponderam que

“. . . é necessário que a história em quadrinhos seja entendida como um produto típico da cultura de massa ou especificamentedaculturajornalística."

De fato, a atual forma das histórias em quadrinhos que tiveram sua origem nos jornais americanos do século passado, passou a ter um personagem constante, a seqüência 
narrativa das imagens e o balão com o texto/ diálogo. O envolvimento imagem etexto dos quadrinhos podem ser classificados como veículo de comunicação de massa (Couperie et al., 1970), uma forma organizada de informação (Klawa e Cohen, 1970), cultura e literatura demassa (Eco, 1970) ou método de comunicação (Eisner, 1989). A compreensão destas imagens como forma de comunicação e informação - largamente utilizadas como meio de publicidade e propaganda - requer umalarga experiência. Desta forma, paraque amensagem sejacompreendida, o desenhista da imagem necessita manter uma interação com o consumidor uma vez que o artista estará evocando imagens armazenadas nas mentes de ambos: comunicador e leitor.

Nestaperspectiva, a históriaem quadrinhos começou a ultrapassar o espaço do divertimento demassapara, a partir daí, influenciar os leitores em esferas psicológicas esociais, porque era uma forma de leitura alternativa. Nascia uma literatura de comunicação visual da cultura de massa. Estudos eavaliações da história em quadrinhos indicaram que o novo meio, que então surgia, possuía e ainda possui um efeito positivo para a educação da leitura e da cultura da imagem.

Denominada ainda arte seqüencial por Eisner (1989) e imagemimaterial por M affesoli (1995), por ser umaforma deexpressãovisual além da matéria, isto é, oriunda do imaginário edo sonho, acentua-sequeas histórias em quadrinhos nasceram do desenho narrativo. Sua técnica de contar histórias por meio de seqüências imagísticas possibilitarama leitura iconográfica e se firmaram como meio de comunicação.

De fato, o público adulto esclarecido, seduzido pelas qualidades formais dos quadrinhos como meio de expressão cultural e social, reconhece o seu papel na mídia e a importância destas imagens no contexto cultural, que vêm perdurando como ponto universal de interesse através da comunicação social .

\section{Referências Bibliográficas}

COMA, J. Historie de los comics. Barcelona: Gustavo Gili, 1979.

COUPERIE, P. et al. História em quadrinhos e comunicação de massa. São Paulo: MAM Assis Chateaubriand, 1970.

DUARTE JR., João Francisco. Fundamentos Estéticos da Educação. São Paulo: Cortez, 1985.

ECO, Umberto. A pocalípticos e Integrados. São Paulo: Perspectiva, 1970.

EISNER, Will. Q uadrinhos e arte seqüencial. São Paulo: Martins Fontes, 1989.

GAIARSA,José. "DesdeaPréHistóriaatéMcLuhan". In:MOYA, A. Shazam. São Paulo: Perspectiva, 1970, pp. 115-120.

GOMBRICH, E. A. Arte e ilusão - um estudo da psicologia da representação pictórica. São Paulo: Martins Fontes, 1986.

KLAWA, L., COHEN, H. "Os quadrinhos e a comunicação de massa”. In: MOYA, A. Shazam. São Paulo: Perspectiva, 1970, pp. 103-124.

LUYTEN, S. 0 que é história em quadrinhos. São Paulo: Brasiliense, 1985.

MAFFESOLI, M. A contemplação do mundo. Porto Alegre: Artes \& Ofícios, 1995.

MOYA, A. História das histórias em quadrinhos. São Paulo: Brasiliense, 1993.

"O mundo da arte". São Paulo: Encyclopedia Britannia do Brasil, 1979, v. 1-2.

PELTZER, G. Periodismo iconográfico. Madrid: Rialp, 1991.

RAHDE, Maria Beatriz. "Histórias em quadrinhos: perspectivas culturais e pedagógicas". Dissertação de Mestrado, Porto Alegre: PUCRS, 1991. 